\title{
Appendix C: Aalborg University ${ }^{1}$
}

\section{Anne Pors Eriksen, Morten Dahlgaard and Charlotte Pedersen Jacobsen (Aalborg University, Denmark)}

\section{C.1 INTRODUCTION OF THE UNIVERSITY AND ITS REGIONAL CONTEXT}

At Aalborg University, we are firmly committed to our strategy 'Knowledge for the World'. We have a long history of building strong bonds to our local community but, at the same time, we aspire to have an impact on the entire world through the highest level of education, research, and engagement in partnerships with regional, national, and international partners. It is not without reason that we define ourselves as being a regional, national, and international university.

Despite our international mind-set, Aalborg University's roots in the region of North Denmark run deep, and we are continuously committed to developing our engagement and collaboration with the regional stakeholders, regional businesses, the region itself, and the public institutions. Our values and ways of collaborating reflect that regional commitment, but we also continue to develop those values and ways of driving both innovation and collaboration forward, by which we raise them to the highest international level. With a population of 587335 people distributed over its 7879 square kilometres, North Denmark is a small region. It is a low densely populated area and has a lower than average GDP per capita with a growth from 2010 to 2014 in North Denmark at $1.59 \%$ compared to $1.63 \%$ on a national level. The region has a higher employment share in manufacturing and agriculture compared to the national level.

The (re-)numbering of sections, tables and graphs in this appendix was done by the book editors, as well as other minor edits to ensure text and format consistency across all appendices $\mathrm{B}$ to $\mathrm{F}$. 
Born out of a merger of established educational institutions and ambitious political forces, the first vision for Aalborg University was to create a strong education centre. Since its establishment in 1974, the university has not only developed an excellent educational programme but also a strong research profile and as of 2018 is ranked in the top 2\% of the world's 17000 universities. $^{2}$ Aalborg is fourth in the world within the field of engineering, and in Europe, it is ranked in first place. ${ }^{3}$ As of 2018, Aalborg University is ranked 23rd among the world's universities under 50 years old. This makes the university the highest ranked Nordic university in the category. The rank today is also a significant climb from 2013 when it was ranked 71st out of the 200 universities included in the list. ${ }^{4}$

Aalborg University's position as a regionally based university, a national university with campuses in both South Denmark and the Capital Region, as well as an internationally established top-class university gives it a unique position as an actor in the development of regional and national innovation policies as well as being a prominent global partner in knowledge transfer, entrepreneurship, and education.

The study format at Aalborg University is problem-based and conforms to the model of Problem-Based Learning (PBL). The PBL model is characterised by problem-solving group work based on real-world projects that are often performed in collaboration with businesses. Fifty-three per cent of the university's master theses are conducted together with external organisations where students work with companies and public institutions throughout their education. ${ }^{5}$ Recently, in a MIT report, ${ }^{6}$ Aalborg University was classed fourth in the world among engineering education institutions. Altogether, this reflects that Aalborg University is able to combine a cross-disciplinary project-oriented teaching model with excellent research that is linked to its regional setting. These key factors enable Aalborg University to not only realise its own ambitions with respect to education and science but also to provide it with the necessary tools to be an active player in the regional innovation agenda.

Since its establishment in 1974, Aalborg University has grown from being a small university with only 1635 students and 421 employees $^{7}$ to having

\footnotetext{
2 https://www.en.aau.dk/research/ranking/.

$3 \mathrm{https} / /$ www.usnews.com/education/best-globaluniversities/search?region=\& subject $=$ engineering \&name $=$.

https://www.aau.dk/forskning/ranking/placeringer/.

Aalborg University Annual Report, 2017.

6 http://neet.mit.edu/wp-content/uploads/2018/03/MIT_NEET_GlobalStateEngi neeringEducation2018.pdf.

7 https://www.en.aau.dk/about-aau/figures-facts/1974-2012/.
} 
20654 students and 3730 employees $^{8}$ in 2017 . This has not only had an impact on the university's position nationally and internationally, but the influence on the region has likewise been immense. Even though the region has seen a decline in the number of employees in regional businesses from 319389 in 1996 to 274420 in 2016, the number of employees with a university degree increased from 12220 to $27545 .{ }^{9}$ With more than 19000 students at the campus in Aalborg as well as 3700 employees, Aalborg University is a large economic factor in the region. Almost six out of ten graduates from the university get a job in the private sector. ${ }^{10}$ Aalborg University has indeed been a regional success.

The main campus of Aalborg University is based in the North Denmark Region. This puts the university in a unique position to play a key role in contributing to the development and execution of the regional innovation agenda and strategic regional innovation objectives. A long-standing cooperation with the municipality and regional growth centre provides continuous interaction between the university and the office for regional development (North Denmark Region). The two parties have a strategic cooperation agreement, stating joint aims on regional innovation.

In our efforts to continuously strengthen the relationship with the region's businesses, Aalborg University has developed a collaboration structure where companies can increase and mature their engagement with the university over time. This facilitates a cooperative learning process and offers a way for the many non-innovative firms in the region to start engaging in R\&I relationships with the university and gradually strengthen these ties. These types of cooperation between regional businesses and the university range from innovation workshops involving students, student projects, and internships to cooperation in clusters and networks and, especially for strong and innovative companies, more contractually binding cooperation such as industrial $\mathrm{PhDs}$, technology transfer, and research projects.

In the North Denmark Region, most companies have less than five employees. Forty per cent are one-man businesses, and only $10 \%$ have more than 20 employees. The university's collaboration structure accommodates and mirrors the needs of the region's large number of small companies and provides them with opportunities to gain and use knowledge from the university. The structure has been a driving force in the region's transfer from an industrial society to a more knowledge-based society.

https://www.aau.dk/om-aau/aau-i-tal/.

Data provided by Region North Denmark: www.rn.dk.

10 Aalborg University Annual Report, 2017 with data from Danmarks Statistik. 
Aalborg University is an active member in several international networks such as the European Consortium of Innovative Universities (ECIU) and the Conference of European Schools for Advanced Engineering, Education, and Research (CESAER), the former having a strong focus on regional innovation activities. As one of the original members of ECIU, Aalborg University has taken an active part in addressing and exploring innovation on all university levels such as best practice, new ways of collaborating, innovation ecosystems, and promotion of entrepreneurial research, education, and innovation. Together with the ECIU member universities, Aalborg University has worked with the HEInnovate assessment tool ${ }^{11}$ to both improve the assessment tool and to actively use it for developing the university's innovation potential. Aalborg University's profile and approach to collaboration and innovation have established Aalborg University's leading role as a regional, national, and international pioneer in pursuing an innovation agenda.

\section{C.2 REGIONAL ORIENTATION, STRATEGIC DEVELOPMENT, AND KNOWLEDGE INFRASTRUCTURE}

Aalborg University considers knowledge transfer and cooperation to be integral parts of the university's DNA. These activities are conducted on several levels, focusing not only on traditional activities of knowledge transfer such as patents, spin-outs, licences, contracts, and research projects but also on informal activities of knowledge transfer such as networks, students-business cooperation, and engagement in well-established national and regional trade promotion activities.

To facilitate and support researchers, educators, and students in these activities, Aalborg University relies on a well-established innovation department (AAU Innovation). The innovation department is deeply rooted in research and education, as well as embedded outside the university in networks, clusters, municipalities, and local business organisations. This way, AAU Innovation is best suited to establish potentially fruitful connections between the university's students and researchers and its many partners. The innovation department supports not only formal knowledge transfers regulated by law, namely contracts and technology transfer, but also entrepreneurial activities, strategic

11 HEInnovate is a self-assessment tool for Higher Education Institutions which wish to explore their innovative potential. The European Commission and the OECD have joined forces in the development of HEInnovate. It is free, confidential, and open to anyone to use (source: https://heinnovate.eu/en). 
funding support, and matchmaking activities. AAU Innovation also provides targeted counsel and support to researchers and organises activities.

The university's focus on collaboration with regional businesses has supported the North Denmark Region's transfer from being an industrial society in the past to a far more knowledge-based society today. Over the years, the partnership between Aalborg University, the Office for Regional Development, and the North Denmark Region has developed and established itself as being mutually beneficial. A strategic cooperation agreement provides common interests and combines the university's strategy with the North Denmark Region's strategy for regional growth and development. The agreement states that Aalborg University and the North Denmark Region will work closely together to improve the development of regional strategic positions of strength. The focus is especially on regional clusters of excellence such as the regional ICT cluster, Brains Business, and the regional hub for energy, House of Energy. Furthermore, the university and the region work together to strengthen entrepreneurship in the North Denmark Region and to retain more graduates in regional companies.

Because Aalborg University and the regional companies are especially strong within the fields of ICT and energy research, well-established regional clusters are embedded in these progressive research communities. The engagement in a cluster has proven beneficial for many businesses as the interaction between companies, regional municipalities, and the university provides a triple helix setting for business development. At the same time, Aalborg University works strategically and is dedicated to adding a fourth element to the triple helix, making it a quadruple helix. The fourth element is civil society and the media, and this strategic approach emphasises the university's acknowledgement of its social responsibility in addition to its role of educating and conducting research. It is also in line with the European Union's approach to developing a competitive and knowledge-based society for the future.

Examples of Aalborg University's commitment to its social responsibility are:

- Lead in creating a 'Universitarium', where children can learn and be engaged in scientific play. ${ }^{12}$

- Making megatrends in society strategic focus areas for research and innovation, e.g. the UN Sustainable Development Goals.

Aalborg University's engagement in science, the region, businesses, and society make it a desired strategic partner for many companies. A report from the Confederation of Danish Industry has established Aalborg as the No. 1

12 https://www.universitarium.dk/om/. 
university in Denmark for businesses to collaborate with. On a scale from 1 to 5, where 5 is 'very satisfying', Aalborg University scored 3.9 with a big gap down to the second placed university with a score of 3.3. The average score for the six Danish universities was 3.0. ${ }^{13}$

According to the report from the Confederation of Danish Industry, Danish companies especially benefit from Aalborg University's agile, pragmatic, and accommodating approach to cooperation. These conclusions are supported by an analysis and mapping of Aalborg University's engagement with companies and public institutions from 2017 . The analysis shows that $85 \%$ of the companies find that their partnership with Aalborg University is fruitful and characterised by strong communication. Furthermore, more than $80 \%$ agree that Aalborg University is very observant and understanding with regard to the company's needs. Almost the same percentage of companies found that Aalborg University is excellent at matching expectations. ${ }^{14}$

\section{C.3 EDUCATION AND HUMAN RESOURCES DEVELOPMENT}

All degree programmes and research activities at Aalborg University are PBL oriented and have a clear interdisciplinary focus. Universities, researchers, and students have nationally and internationally recognised the university's PBL pedagogical model as advanced and efficient. The statements are underlined by the fact that UNESCO has placed its only Danish chair in PBL at Aalborg University.

Through strong interplay between staff and students and with intense collaboration with public and private sectors, Aalborg University offers world-class teaching and degree programmes with a real-world approach. In a MIT report, ${ }^{15}$ Aalborg University was appointed fourth in the world among engineering education institutions.

Among MIT's reasons for naming Aalborg University one of the world's leading institutions within engineering education are:

- Aalborg University is focused on continuously developing its educational programmes.

\footnotetext{
$13 \mathrm{https} / / / \mathrm{www}$.danskindustri.dk/arkiv/analyser/2018/2/danmark-tilbage-pa -vidensporet-iv/.

14 http://www.aau.dk/digitalAssets/307/307540_aalborg-universitets -vidensamarbejde-effekter.pdf.

15 http://neet.mit.edu/wp-content/uploads/2018/03/MIT_NEET_GlobalStateEngi neeringEducation2018.pdf.
} 
- Aalborg University is extraordinarily successful in making great graduates out of students who initially did not have the required skill set.

- Aalborg University has a strong evidence-based approach to teaching, which makes the university a current leader in engineering education. The report from MIT highlights Aalborg University's investment in developing new models of problem-based learning for the digital age with a view to implementing such approaches at the university.

The PBL model teaches students to acquire knowledge and skills independently and to work in an interdisciplinary way and to be problem and result oriented. This makes the model ideal in preparing the students for working together with the business community, which not only develops the students' academic skills but also hones their skills in team work and cross-disciplinary cooperation. The PBL teaching method makes the candidates at Aalborg University a sought-after resource in the labour market, as they can work both independently and with other professionals. Throughout their education, students work on real cases, interacting with companies and public institutions, and the university's approach to teaching leaves the students well prepared for real job situations.

To keep the university as a world leader in education, Aalborg University will invest DKK 9 million over the next three years in further developing its approach to teaching. The new teaching model is likely to bring mixed method approaches to problem-based learning. This will be supported by virtual projects, international linkages, and online learning.

In order to ensure the success of its students and graduates, Aalborg University publishes a guide once a year, which gives businesses an insight into the different educational programmes at the university and what skills the students hold. ${ }^{16}$ The guide is designed so that businesses can search for certain skills and then find out which programmes they should hire candidates from. It is a way for the university to present to the business community its graduates' skills instead of graduates with hard to understand titles. For the businesses, it becomes far easier to find the next valuable employee. Aalborg University also promotes students to businesses as potential collaborators on projects or workshops. Collaborations during study years often lead to employment after graduation.

Aalborg University's graduate analysis from 2017 showed that $67 \%$ of graduates collaborated with a company or public institution as part of a project during their academic education. The same analysis showed that $31 \%$ of the graduates secured a job before the end of their education and a further $31 \%$ had

$16 \mathrm{http}: / / w w w . e-p a g e s . d k / a a l b o r g u n i v e r s i t e t / 534 / \mathrm{html} /$. 
a job within 0-3 months ${ }^{17}$ and $57.6 \%$ of graduates from Aalborg University found employment in the private sector. ${ }^{18}$

\section{C.4 RESEARCH, TECHNOLOGICAL DEVELOPMENT, AND KNOWLEDGE TRANSFER}

Knowledge transfer is conducted on many levels at Aalborg University. The university's researchers produced 5415 research publications in 2017, engaged in 2945 research projects with external partners, and conducted 1225 student projects in collaboration with companies. ${ }^{19}$ Twenty-nine Danish researchers are among the world's most cited and seven of those are from Aalborg University. ${ }^{20}$ However, the more traditional technology transfer activities such as patent applications, inventions, licences, and spin-outs are also an integrated part of Aalborg University's way of exchanging and sharing knowledge (see Table C.1). As in all other aspects of knowledge transfer, collaborations between the university and companies play a significant role.

Table C.1 Key figures on research, technology and innovation (2017)

\begin{tabular}{lr}
\hline Research publications & 5415 \\
Teaching and dissemination publications & 569 \\
Patent applications & 16 \\
Sold and licensed inventions & 42 \\
Spin-out companies & 1 \\
Reported inventions & 71 \\
Number of student projects with companies & 1225 \\
Number of external projects & 2945 \\
Financial extent of cooperation with companies & $€ 152 \mathrm{M}$ \\
\hline
\end{tabular}

An increase in technology transfer from 2006 onward marked a change in Aalborg University's commercial strategy. Since 2006, the university has dedicated staff to all aspects of technology transfer, in-sourcing the entire commercial process and limiting patenting to where it makes sense commercially as well as strategically. This change has led to Aalborg University being the university in Denmark that sells most inventions and discoveries. From

\footnotetext{
17 http://www.e-pages.dk/aalborguniversitet/666/html5/.

Aalborg University Annual Report 2017 with data from Danmarks Statistik.

Aalborg University Annual Report 2017.

https://www.aau.dk/digitalAssets/418/418275_aau_1974-og-2018.pdf.
} 
2012 to 2016, Aalborg University was behind 36\% of all commercialisation of research outputs. ${ }^{21}$

Figure C.1 shows the number of invention disclosures in relation to the number of commercial technology transfers between 2000 and 2014. The statistics are compiled on the basis of the official data on the commercialisation of research results. This is published annually by the Danish Agency for Science, Technology, and Innovation. The number of commercial technology transfers reflects the sum of licence fees, sales, and opposition agreements as well as the number of established spin-off companies.

At Aalborg University, an agreement about transferring technology to a company is often combined with a close collaboration between the company and relevant researchers. A partnership ensures that technology is transferred or licensed in the best possible way and also makes it possible for the company, the inventors, and the research staff to further develop the technology to suit the company's needs. This way of addressing technology transfer also encourages and develops cooperation between companies and researchers. The approach is adopted in licensing, sales, and spin-outs, making technology transfer at Aalborg University not just about patenting but just as much about enhancing cooperation between researchers, students, and companies. Each year, Aalborg

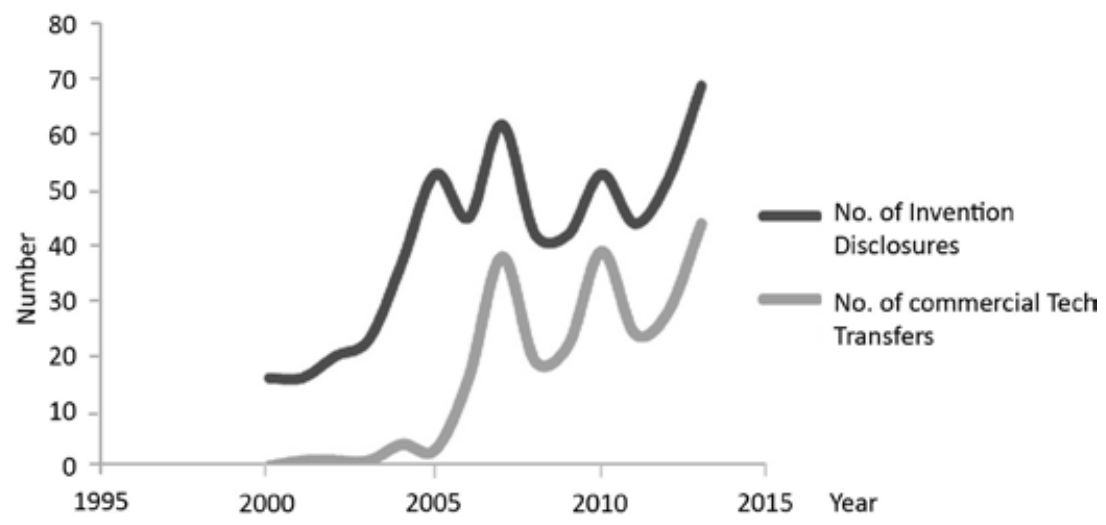

Figure C.1 Invention disclosures and commercial technology transfers

21 Ministry of Education and Research (2016). Knowledge for growth: Publicprivate interaction on research (average for the period 2012-2016); Uddannelses- og Forskningsministeriet (2016). Viden til vækst: Offentlig-privat samspil om forskning (gennemsnit for perioden 2012-2016). 
University negotiates 300-400 contractually binding research collaborations with both public institutions and private companies. ${ }^{22}$

Aalborg University provides companies with the possibility to test an invention through Open Innovation Licensing (OIL) before buying it. This online platform supports innovators in their quest for knowledge by making new technological inventions easily and conveniently accessible. Whether you are a company representative, researcher, or student, OIL can provide the necessary technology for your latest project. Aalborg University believes in risk-free technology licensing, and this platform provides the user with a trial licence. The licensing system makes sure that technology matches the intended needs and that it integrates well within the organisation before the user pays for it. The OIL programme introduces a two-step licensing process, enabling clients to try technologies on non-commercial terms before signing on for a commercial licence.

\section{C.5 ENTERPRISE DEVELOPMENT AND ENTREPRENEURSHIP}

Aalborg University has set a vision for 2021, which includes:

- All students must graduate with the knowledge and skills to create their own company;

- All students must be highly employable;

- The university is recognised for its ability to develop start-up companies;

- The university must develop an evidence-based method for creating entrepreneurs;

- A goal is to create 1000 entrepreneurs within the next strategic period (2021-2026).

These ambitious goals are founded in a long-standing tradition of working with visionary entrepreneurs as well as the general strong ties between the PBL teaching model and entrepreneurial methods and thinking.

As a modern university, Aalborg University is expected by both students and stakeholders to support entrepreneurship and enterprise development. It is part of a deep-rooted culture, deriving from the foundation of the university, and many of the leading and pioneering companies in the North Denmark Region have indeed been founded by graduates from Aalborg University.

22 Ministry of Education and Research (2016). Knowledge for growth: Publicprivate interaction on research (average for the period 2012-2016); Uddannelses- og Forskningsministeriet (2016). Viden til vækst: Offentlig-privat samspil om forskning (gennemsnit for perioden 2012-2016). 
With its geographic location and distance to the capital, the North Denmark Region has had a long history of needing to set up its own structures to support entrepreneurship in a region with few investors and only little risk capital. In the past 15 years, Aalborg University has been able to secure funding from private foundations to build early-stage funding programmes for research-based entrepreneurs. Supporting Entrepreneurship at Aalborg University (SEA) has worked with both students and researchers to manage programmes since 2003 for students and the incubator, as well as to advance entrepreneurial education in collaboration with researchers and professional business developers. It is paramount for Aalborg University to further develop its entrepreneurial activities, and the university's strategy focuses directly on developing a flexible incubator environment. This is underpinned by both the incorporation of entrepreneurial activities in the PBL teaching method and by promoting an entrepreneurial mind-set in the students and researchers. Aalborg University also accomplishes this by engaging in more professional entrepreneurial activities such as extracurricular entrepreneurial classes and guidance in business development.

Aalborg University works closely with regional business partners, the regional Growth House, and the municipality to establish cross-organisational entrepreneurship activities, which support entrepreneurs throughout their business development. By doing so, the university facilitates the continuous support of entrepreneurs even when they move from student to graduate to alumni.

Aalborg University has more than 100 different courses or study programmes on entrepreneurship for students who want to start their own company. Entrepreneurial activities are also incorporated in the regular teaching to develop the students' entrepreneurial mind-set and prepare them for work in the challenging environment of many real life companies. AAU Innovation also supports entrepreneurship by developing entrepreneurial processes that can be integrated into educational programmes.

In 2017 alone, 72 teams worked in the university's incubator, and Aalborg University's business developers worked with more than 200 students. ${ }^{23}$ The entrepreneurial mind-set is essential in all aspects of education at Aalborg University.

To promote the international dimension, Aalborg University also cooperates with other universities in Europe. Amongst others, the university has joint entrepreneurial activities with Dublin City University and works within the frame of the European Consortium of Innovative Universities (ECIU).

23 Data source: AAU Innovation entrepreneurial team. 
Aalborg University also works hard to make strong ties to the business community. The concept of 'co-location and co-creation' is blossoming all over Europe. It is a new way of thinking and creating knowledge that bridges universities and society. The approach of co-creation is also an inseparable part of Aalborg University's DNA. It builds on the understanding that research, education, and practice are integrated and create mutual impact. The other key element in the concept of co-location and co-creation is the belief that co-location breeds co-creation. This belief forms the basis for the way each campus at Aalborg University is set up so that companies located on site pave the way for day-to-day and long-term strategic cooperation between researchers, students, and the embedded companies.

The aim of Aalborg University's collaboration with the business community through companies located on campus is:

- To promote, enhance, and utilise binding collaboration between the university and the business community;

- To enable the university's knowledge to become influential in the outside world;

- To ensure practical and theoretical contributions from collaborative companies;

- To support business development by promoting initiatives in establishing start-ups and by promoting business incubation.

Co-location and co-creation are not about a link to the university via a science park facility; they are all about being located and embedded in the research and student communities at campus. Hereby, the business community stimulates and creates an innovative ecosystem at campus, which contributes to the larger ecosystem in the surrounding region. Through collaboration with the university, the business community can hopefully have an international research-based impact.

\section{C.6 VISION AND STRATEGY FOR THE NEAR FUTURE}

Aalborg University currently consolidates and further develops its profile as a dynamic and innovative research and educational institution that is oriented towards the world. Over the past three years, the university has experienced a 50\% increase in earnings from the university's cooperation with external partners. External funding is expected to increase going forward.

The university's focus on interacting with its surroundings on both a small and large scale is fundamental in its strategy 'Knowledge for the World'. The strategy sets the framework and ambitions for the core activities of research, 
education, and knowledge cooperation. Because knowledge cooperation is an integral part of the strategy for excellent research and education, it also plays a vital role in the daily work for both students and researchers. 'Knowledge for the World' is filled with great ambitions for knowledge cooperation to be both an integral part of research and education and in consolidating Aalborg University's position as a leading engaged university. The university's dedication to developing the areas of innovation and cooperation becomes evident in its strategic focus as well as the construction of a new Science and Innovation Hub.

The Science and Innovation Hub will be housed in a new building which provides space for both lively research and focused concentration in order to promote innovation and the development of new ideas. The users will be able to inhabit a new type of non-programmed workshop space ('garages') referring to the architectural framework for some of the world's most successful entrepreneurs. In these garages, the users define their own rules and methods of co-working, creating spaces for new ideas to flourish. The garages are the innovative basis for informal learning, acting as a supplement to the formal education and research offered at Aalborg University. The new Science and Innovation Hub building will be ready in 2021 and will form the physical surroundings for Aalborg University's entrepreneurial, innovation, and cooperation activities. The Science and Innovation Hub is and will be supplemented by thematic incubators placed in research labs. At present, there is one incubator hub at Aalborg University, but work is being done on establishing four more: in Copenhagen, Esbjerg and two more in Aalborg. The three incubator hubs in Aalborg will have different foci. As an example, one will focus on health.

Starting in 2019, Aalborg University will initiate a project with data-driven management in innovation. Going forward, AAU Innovation will also work in a targeted way towards making the university's partnerships data-driven. This means that, in the future, the university will be able to:

- More clearly document the effects of collaborations with supportive data;

- Use data to make sure that the university has the right options for collaboration 'readily available'.

In 2018 and 2019 Aalborg University also conducted several analyses concerning entrepreneurship and collaborations with external partners. The aim of the analyses is to answer the following questions:

- A comparative analysis of entrepreneurship among Danish universities. How many entrepreneurs do the universities produce, who are they, and how do they fare?

- What kind of companies generally engage in collaborations with Aalborg University and how do they benefit from it? 
Aalborg University has a cooperation agreement with the regional Growth Forum, which initiates and monitors projects and sets the strategic focus for the business development of the North Denmark Region. As the cooperation agreement is based on the strategies for both organisations, it combines the needs from the business community, the public institutions, and the university, providing a strong focus on common interests. As an example, the strategic cooperation agreement has a special focus on cooperation with small and medium-sized companies. This contributes to increasing the small businesses capacity for innovation and strengthens the level of innovative companies in the region, as well as to mature companies, for increased research cooperation with the university. This form of strategic cooperation agreement is expected to raise the number of highly educated employees within the region and to continuously support the region's transformation from a region of industry and agriculture to a highly developed technological and knowledge-based region. 